\title{
RANCANG BANGUN SISTEM INFORMASI PENJUALAN SEPATU BERBASIS WEBSITE DENGAN METODE WATERFALL
}

\author{
Ibnu Dwi Lesmono \\ Program Studi Manajemen Informatika, AMIK BSI Purwokerto \\ JI. DR. Bunyamin No.106 Pabuaran, Purwokerto Telp. (0281) 642848 \\ Ibnu.idl@bsi.ac.id
}

\begin{abstract}
Abstrak
Seiring dengan bertambah pesatnya penggunaan internet, situs penjualan atau e-commerce muncul memberikan kemudahan bagi masyarakat dalam bidang pencarian informasi serta kebutuhan. Perkembangan e-commerce dapat memicu timbulnya usaha di bidang apapun pada dunia maya. Perancangan sistem informasi penjualan sepatu berbasis web untuk memberikan pelayanan yang lebih baik lagi bagi pelanggan dan mempermudah dalam membeli produk sepatu. Pada pembuatan aplikasi web penjualan menggunakan model pengembangan perangkat lunak Waterfall dan rancangan aplikasi menggunakan metode struktural Entity Relationship Diagram (ERD). Dalam pembuatan aplikasi menggunakan PHP sebagai bahasa script dan XAMPP sebagai database tempat penyimpanan data. Program diuji dengan menggunakan metode Blackbox dengan memasukan data-data yang telah ada Teknik pengumpulan data yang digunakan dalam penulisan ini adalah dokumentasi, wawancara, dan studi pustaka. Metode pengembangan perangkat lunak yang digunakan adalah waterfall ( air terjun). Berdasarkan hasil penelitian pengembangan website sangat penting terutama untuk mengatasi persaingan bisnis sekarang ini khususnya penjualan sepatu, dalam melakukan kegiatan transaksi mulai dari proses order, menyimpan data produk, mengubah data produk serta menghapus data produk sehingga menghasilkan informasi yang cepat, tepat, akurat dan menarik bagi pelanggan.
\end{abstract}

Kata Kunci: Blackbox, E-commerce, PHP, Sepatu, Waterfall

\begin{abstract}
Along with the increasing use of the internet, sales sites or e-commerce appear to provide convenience for the public in the field of information search and needs. The development of ecommerce can lead to the emergence of business in any field on the virtual world. Designing a web-based shoe sales information system to provide better service for customers and make it easier to buy shoe products. In making web application sales using Waterfall software development model and application design using structural method Entity Relationship Diagram (ERD). In the making of the application using PHP as a scripting language and XAMPP as a database of data storage. The program is tested by using the Blackbox method by entering the data that already exist Data collection techniques used in this paper is the documentation, interviews, and literature study. Software development method used is waterfall (waterfall). Based on the results of research website development is very important especially to overcome the current business competition, especially the sale of shoes, in conducting transaction activities from the order process, store product data, change product data and delete product data to produce information fast, precise, accurate and interesting customer.
\end{abstract}

Keywords: Blackbox, E-commerce, PHP, Shoes, Waterfall

\section{Pendahuluan}

Perkembangan teknologi khususnya teknologi informasi berkembang sangat pesat. Saat ini sering mendengar mengenai teknologi internet yang merupakan perkembangan terkini dari teknologi informasi. Perkembangan teknologi lebih banyak berkembang kearah user friendly, 
yang artinya semakin mempermudah pemakai dalam memahami serta menjalankan fungsi internet tersebut. Dimasa lalu, aktivitas dunia perdagangan (ecommerce) dilakukan melalui penawaran langsung tapi pertumbuhan drastis dari internet telah mengubah paradigma tersebut. Pemakaian system e-commerce sangat menguntungkan banyak pihak, baik konsumen, produsen maupun penjual. Melalui internet, pedagang dapat menawarkan produknya secara online kepada pembeli tanpa perlu bertatap muka. E-commerce (perdagangan melalui internet) mengizinkan pedagang untuk menjual produk-produk dan jasa secara online. Calon pembeli atau konsumen dapat menemukan website penjual, membaca, melihat produk-produk dan memesannya secara online.

(http://www.ejournal.unsa.ac.id/diunduh:1905-2014).

Website e-commerce atau toko online adalah suatu website yang bertujuan untuk menjual satu atau lebih barang dan jasa dengan menggunakan media elektronik sebagai media penyampaian informasi dan media transaksi barang/jasa tersebut. Transaksi pada website e-commerce atau toko online dapat dilakukan dengan cara langsung pada website tersebut dengan menggunakan kartu kredit atau layanan perbankan online. Atau dengan menggunakan transfer melalui rekening bank atau menggunakan jasa perbankan lainnya.

Sepatu merupakan suatu jenis alas kaki (footwear) yang biasanya terdiri bagianbagian sol, hak, kap,tali, dan lidah. Pengelompokkan berbagai jenis sepatu biasanya dilakukan berdasarkan manfaat atau tipenya, seperti sepatu dansa, sepatu resmi (pesta), sepatu santai (kasual), sepatu olahraga, sepatu kerja dan masih banyak yang lainnya. Biasanya, ukuran sepatu mengikuti beberapa standar dan berbeda di seluruh dunia. Di area perkotaan sepatu seperti menjadi kebutuhan primer (kebutuhan) karena hampir setiap saat orang di kota memakai sepatu untuk melakukan kegiatan. Orang di kota juga memakai sepatu ketika pergi ke sekolah atau bekerja. sepatu sangat berguna untuk kehidupan sehari-hari juga misalnya untuk pergi ke pertemuan resmi maupun untuk olah raga, untuk pergi ke pesta, untuk menonton bioskop juga bisa supaya terkesan elegant jika ada teman yang melihat penampilan seseorang.

Banyaknya peminat sepatu dikalangan muda dimanfaatkan oleh beberapa orang. Contohnya banyak peluang bisnis yang menggunakan media elektronik dan komputer sebagai alat pengolah data berbagai kegiatan. Dengan ketatnya persaingan di dunia bisnis, maka perlu adanya media periklanan dan pengolah data yang dapat memberikan kemudahan, kecepatan dan ketepatan bagi pengguna juga kemudahan kepada konsumen untuk mencari dan mendapatkan suatu produk dengan mudah.

Melihat pergerakan teknologi semakin pesat, serta persaingan usaha yang semakin terlihat, perusahaan dapat memanfaatkan teknologi internet tersebut untuk menunjang kegiatan perusahaan dengan membangun website dalam bidang penjualan untuk dapat mempromosikan produknya melalui website, website dapat dijadikan sebagai sarana untuk bertransaksi jual beli barang atau produk yang membuat transaksi penjualan dapat dilakukan dengan waktu relatif singkat walau jarak berjauhan

\section{Metode Penelitian}

Dalam usaha pengumpulan datadata yang dapat membantu penelitian ini peneliti menggunakan metode penelitian sebagai berikut :

\subsection{Metode pengembangan perangkat lunak}

Metode yang digunakan pada
pembuatan sistem menggunakan model water fall yang terbagi menjadi tiga tahapan, yaitu :

\section{a. Analisa kebutuhan}

Pada tahapan ini, analisa kebutuhan sistem dilakukan untuk membantu menjabarkan kebutuhan pengguna menjadi desain sistem yang kemudian akan dibuat menjadi program aplikasi. Dalam hal ini admin memiliki hak akses untuk masuk ke halaman admin dengan cara melakukan login terlebih dahulu dan mengolah semua data yang ada di halaman admin. Sedangkan user (pengguna) tidak berhak masuk dalam halaman admin. User (pengguna) hanya memiliki akses seperti melihat produk yang dijual dan melakukan transaksi penjualan ketika menjadi member untuk membeli sebuah Sepatu.

b. Perancangan sistem dan perangkat lunak 
Pada tahap desain, peneliti menggunakan Cascading Style Sheet (CSS) yang terdapat dalam software Adobe Dreamweaver CS3. Untuk perancangan aplikasinya peneliti menggunakan struktur navigasi campuran. Pada tahap perancangan basis data peneliti menggunakan Entity Relational Database (ERD) sebagai alat untuk merancang relasi antar tabel dalam database untuk kemudian dikonversi ke dalam bentuk Logical Record Structure (LRS). Pada tahap pembuatan kode program peneliti menggunakan bahasa pemrograman PHP dan MYSQL yag dituangkan kedalam software Adobe Dreamweaver CS3 dengan menggunakan XAMPP sebagai web server.

c. Implementasi dan pengujian unit Dalam melakukan pemrograman peneliti melakukan pengujian terhadap kode-kode program untuk memastikan kebenaran program tersebut.

Pengujian ini dilakukan untuk mencari kesalahan yang ditimbulkan ksarena salah tulisan atau kesalahan pemrograman. Dalam pengujian sistem e-commerce penelitian menggunakan metode black box testing. Hal ini dilakukan untuk mencari posisi kesalahan (error) dan memastikan keluaran yang dihasilkan sesuai yang diinginkan.

\subsection{Teknik pengumpulan data}

Teknik pengumpulan data yang digunakan oleh peneliti dalam pembuatan penelitian adalah :

\section{a. Observasi}

Dimana peneliti menggunakan metode ini dengan cara peneliti melakukan pengamatan langsung di sosial media dan catatan-catatan kejadian pada website ecommerce sejenis yang telah ada sebelumnya.

\section{b. Studi kepustakaan}

Peneliti mendapatkan banyak tambahan dengan membaca buku-buku atau literature yang mewakili judul penelitian penelitian yang dibahas khususnya yang berhubungan dengan penjualan online (ecommerce).

Metode pengembangan perangkat lunak yang digunakan pada sistem informasi ini adalah waterfall. Menurut

(Sommerville, 2011) ada 5 tahapan dari model waterfall, yaitu mendefinisikan kebituhan; (2) desain perangkat lunak dan sistem; (3) implementasi dan pengujian unit; (4) integrasi dan pengujian sistem; (5) operasi dan pemeliharaan. Metode ini merupakan metode yang sering digunakan oleh penganalisa sistem pada umumnya. Inti dari metode waterfall adalah dengan pengerjaan sari satu sistem dilakukan secara berurutan atau secara linear. Jadi setiap tahap harus diselesaikan terlebih dahulu secara penuh sebelum diteruskan ke tahap berikutnya untuk menghindari terjadinya pengulangan tahapan. Seracara garis besar metode waterfall mempunyai langkah - langkah sebagai berikut.

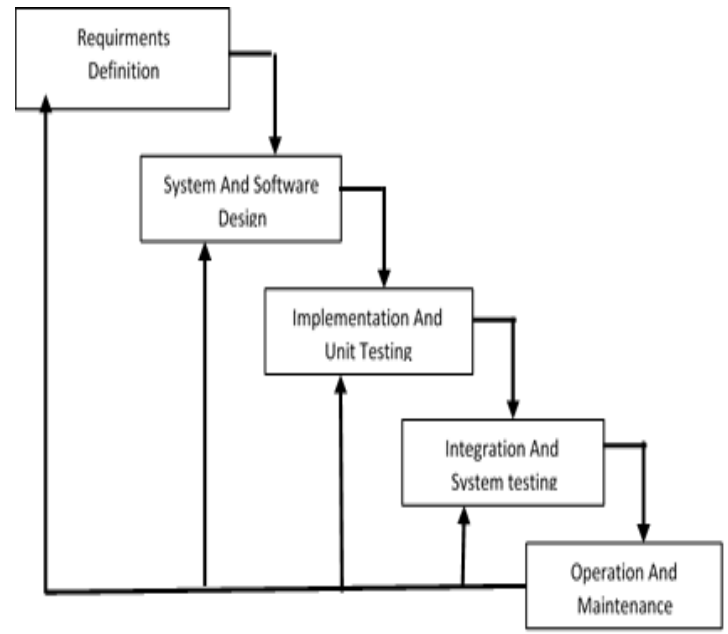

Gambar 1. Model Waterfall

\section{Hasil dan Pembahasan}

Pada bagian ini, dijelaskan hasil penelitian dan pada saat yang sama diberikan pembahasan yang komprehensif. Hasil dapat disajikan dalam gambar dan spesifikasi detil, dan lain-lain yang membuat pembaca memahami dengan mudah. Bab ini berisi mengenai segala sesuatu yang dibutuhkan untuk dapat melakukan analisis kebutuhan perangkat lunak (software requirement analysis).

\subsection{Analisa Kebutuhan}

Hal pertama yang perlu dilakukan dalam analisa kebutuhan dengan mengidentifikasi kebutuhan yang diperoleh berdasarkan kebutuhan pengguna dan kebutuhan sistem.

1. Analisa Kebutuhan Pengguna

a. Administrator 
1) Admin dapat menambah, mengedit serta menghapus data admin.

2) Admin dapat menambah, mengedit serta menghapus data produk.

3) Admin dapat mengedit atau mengganti harga produk.

4) Admin dapat menambah serta menghapus menu kategori.

5) Admin dapat melihat pelanggan yang sudah menjadi member.

6) Admin dapat melihat pesanan dari customer.

b. Pengunjung (user)

1) Pengunjung dapat melihat-lihat produk yang ditawarkan di website.

2) Melihat dan memberi testimonial pada website.

c. Pelanggan (member)

1) Pelanggan dapat melihat-lihat produk yang ditawarkan di website.

2) Pelanggan dapat melihat dan memberi testimonial pada website.

3) Pelanggan dapat melakukan transaksi pembelian.

4) Setelah pelanggan memilih produk, kemudian masuk kedalam keranjang belanja, kemudian masuk ke transaksi pembayaran, apabila produk sudah terkirim, maka pengunjung mengecek di konfirmasi.

2. Kebutuhan sistem untuk pelanggan.

a. Menyediakan form pendaftaran untuk pengunjung yang berminat menjadi member, yang berisikan :
1. Nama
2. Alamat
3. Telepon
4. Email
5. User
6. Password
7. Re Password

b. Menyediakan layanan untuk komentar.

c. Menyediakan layanan transaksi pembelian.

d. Memberikan informasi tentang produkproduk sepatu.

\subsection{Perancangan Perangkat Lunak}

Spesifikasi rancangan perangkat lunak pada pembuatan website penjualan sepatu adalah sebagai berikut:

1. Rancangan Antar Muka

Berikut rancangan antar muka (interface) dan isi (content) dari website penjualan sepatu online berbasis web yang peneliti telah rancang.
Halaman login admin menampilkan menu login untuk mengisi username dan password untuk bisa masuk keruang admin atau halaman admin.

Pada halaman user akan ditampilkan menu atau halaman beranda, produk Sepatu, cara order, kontak, kategori, testimonial, dengan cara mengklik salah satu link menu tersebut, maka pengguna website dapat melihat detail menu yang dipilih tersebut.

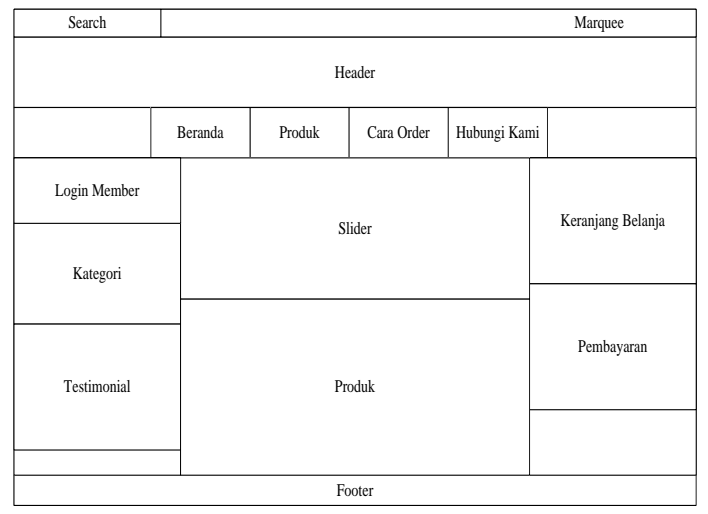

Gambar 1. Bentuk Rancangan Antar Muka Admin

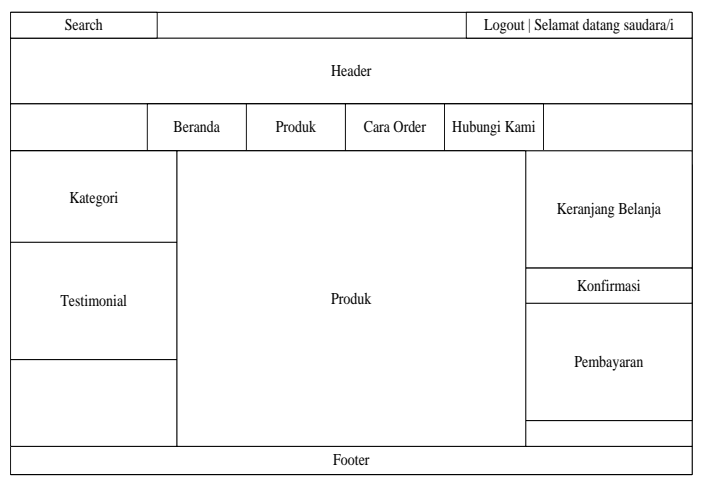

Gambar 2. Bentuk Rancangan Antar Muka member

\subsection{Rancangan Basis Data}

Perancangan basis data menghasilkan pemetaan tabel-tabel yang digambarkan dengan Entity Relationship Diagram 


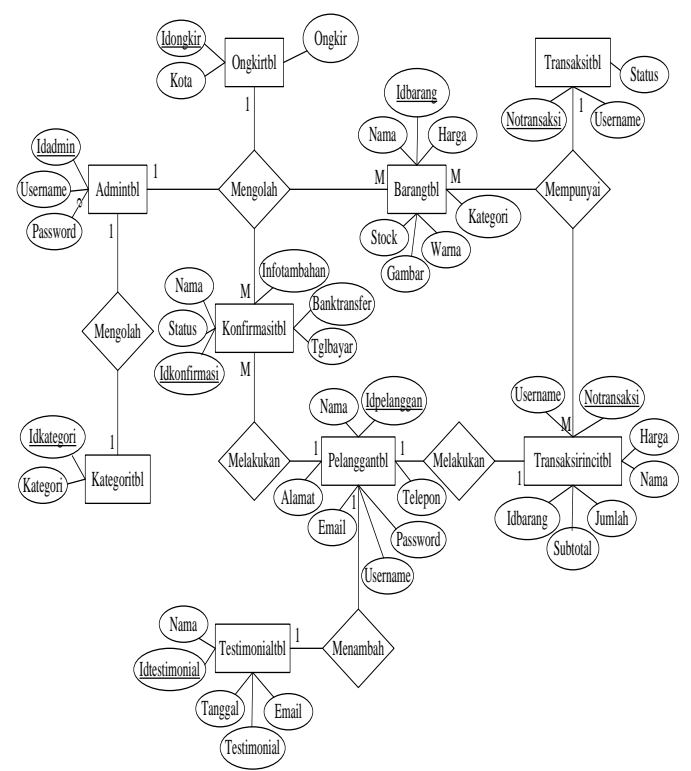

Gambar 3. Entity Relationship Diagram

Perancangan basis data menghasilkan pemetaan tabel-tabel yang digambarkan dengan Logical Relational Structure.

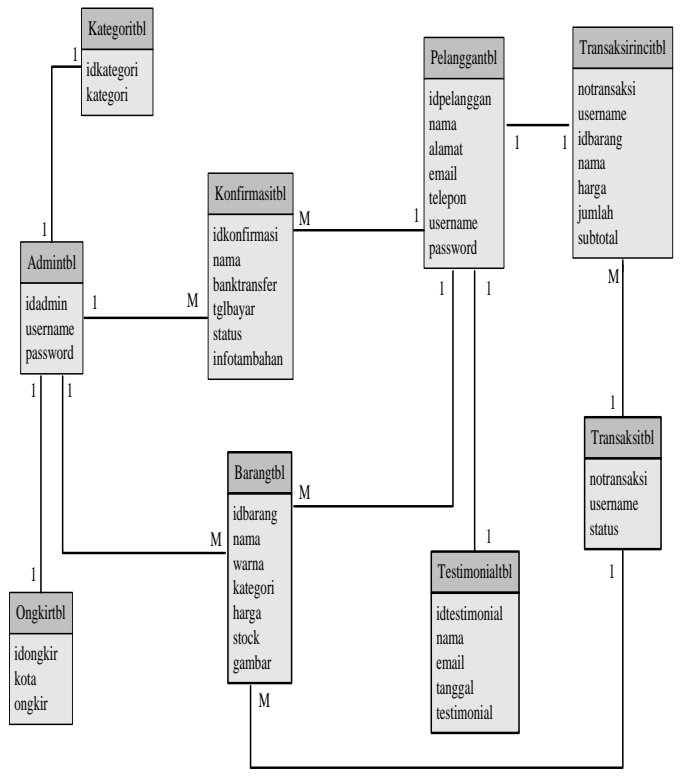

Gambar 4. Logical Relational Structure

\subsection{Rancangan Struktur Navigasi}

Struktur navigasi yang dipakai dalam pembuatan website ini adalah struktur navigasi campuran.
A. Media Admin

Struktur navigasi penjualan sepatu adalah sebagai berikut:

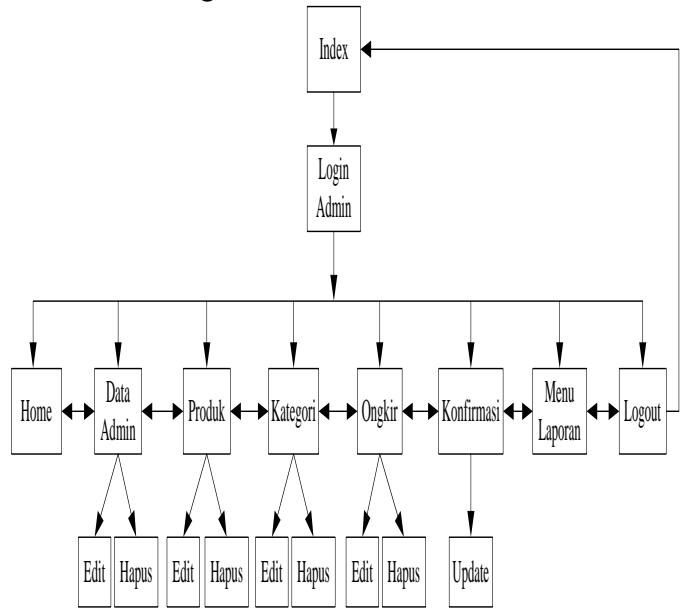

Gambar 5. Rancangan Struktur Navigasi

Admin

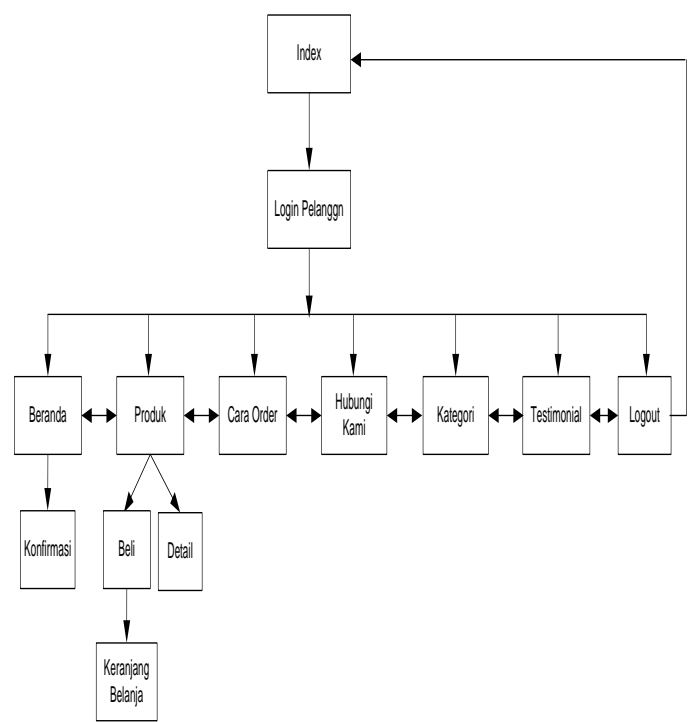

Gambar 6. Rancangan Struktur Navigasi

Pelanggan 


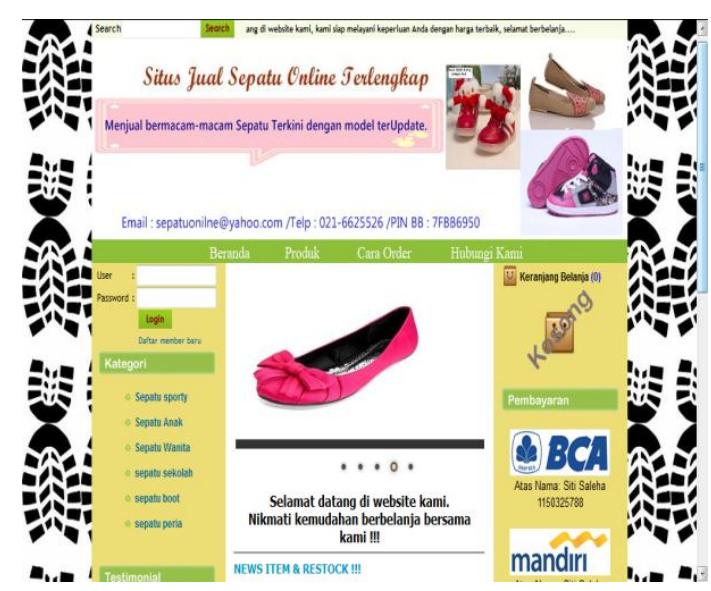

Gambar 7. Tampilan Halaman Awal

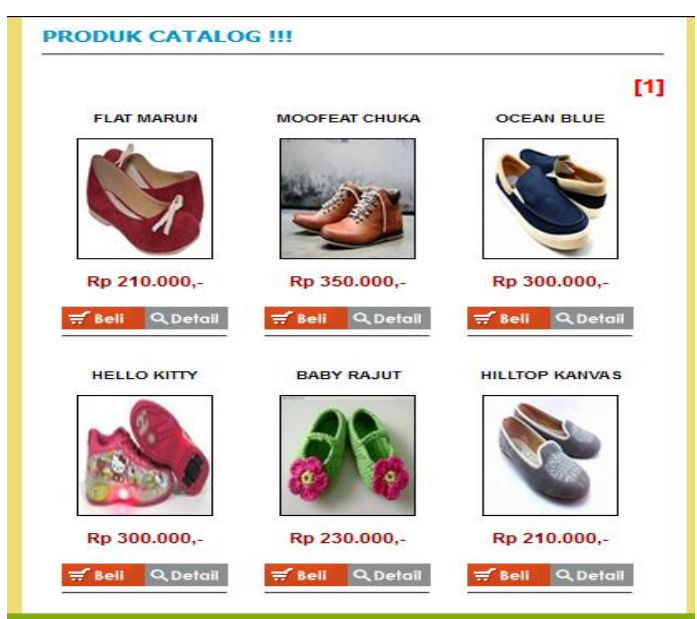

Gambar 8. Tampilan Halaman Produk

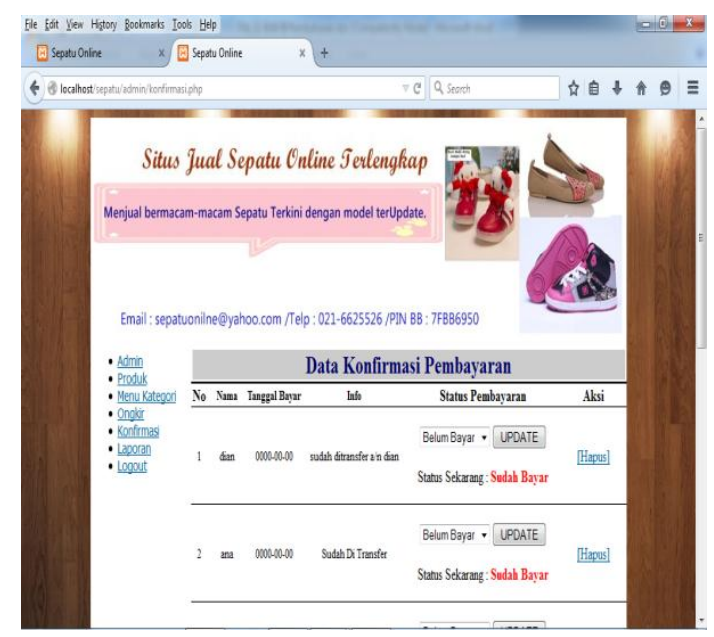

Gambar 9. Halaman Konfirmasi Pembayaran

\subsection{Spesifikasi Sistem Komputer}

Berikut ini adalah spesifikasi perangkat keras dan perangkat lunak minimum yang dibutuhkan untuk mengimplementasikan aplikasi e-commerce pada penjualan sepatu online ini.

1.Spesifikasi Perangkat Keras

Perangkat Keras (Hardware) merupakan seluruh komponen peralatan pendukung yang berbentuk sistem komputer dan peralatan lainnya yang memungkinkan komputer melaksanakan tugasnya, termasuk juga mesin-mesin pembantu penyimpanan data dan alat komunikasi lainnya. Adapun perangkat keras (Hardware) yang dipergunakan dalam perancangan program penelitian penelitian ini adalah sebagai berikut:
A. Server
1. CPU
a. Processor Pentium Dual Core
b. RAM 1 GB DDR3
c. Hard Disk 520 GB Storage

2. Mouse

3. Keyboard

4. Monitor : 12 Inch HD LED

5. Koneksi internet dengan kecepatan 7,2 Mbps

6. Printer: Inject

B.Client

1. CPU
a. Processor Pentium Dual Core
b. RAM 1 GB DDR Memory
c. Hard disk $320 \mathrm{~GB}$ Storage

2. Mouse Trackpad

3. Keyboard

4. Monitor dengan resolusi layar minimum $1024 \times 768$

5. Koneksi internet dengan kecepatan 2 Mbps

2. Spesifikasi Perangkat Lunak Perangkat lunak (software) merupakan komponen dalam data processing sistem yang berupa programprogram dan teknik lain untuk mengontrol sistem. Fungsi software ini adalah bentuk mengidentifikasi dan menyiapkan aplikasi program sehingga tata kerja seluruh peralatan komputer dapat terkontrol, serta membuat pekerjaan lebih efisien. Adapun perangkat lunak (Sotware) yang dipergunakan dalam perancangan program penelitian Penelitian ini adalah sebagai 
berikut:

1. Server

a. Sistem operasi windows 7 Ultimate

Sistem operasi yang digunakan peneliti dalam pembuatan website yaitu windows 7, karena sudah digunakan oleh pengguna laptop maupun Personal Computer (PC) dan sistemnya yang mudah digunakan dan sudah dimengerti oleh penggunanya.

\section{b. Program aplikasi (application sotware)}

Software yang digunakan peneliti dalam pembuatan website yaitu Adobe Dreamwaver CS3, program aplikasi ini digunakan untuk mengedit html, editor profesional untuk mendesain secara visual.

C. Xampp 1.6.4

Paket program ini berisi diantaranya:

1) Apache Web server yang berfungsi menerima dan mengolah permintaan browser web

2) PHP script language berfungsi sebagai pengolah data dari komputer client atau dari komputer server sendiri.

3) MySQL sebagai database untuk menyimpan dan mengolah data yang dinamis dari sebuah aplikasi web.

4) PhpMyadmin yang berfungsi membuat database tanpa melalui console mysql.

d. Mozilla Firefox

Program ini digunakan sebagai penerjemah dari bahasa PHP, HTML, Java Script, XML dan CSS kedalam bahasa atau tampilan yang dimengerti manusia.

2. Client

a. Sistem operasi yang umum digunakan seperti : Microsoft Windows atau Linux (ubuntu, fedora dan lain-lain).

b. Aplikasi web browser seperti Mozilla Firefox, Opera Mini, dan Google Chome.

\section{Kesimpulan}

Berdasarkan pembahasan Rancang Bangun Sistem Informasi Penjualan Sepatu Berbasis Web secara keseluruhan pada bab-bab sebelumnya, maka peneliti dapat mengambil kesimpulan sebagai berikut:

Pengembangan website sangat penting terutama untuk mengatasi persaingan bisnis sekarang ini khususnya penjualan sepatu, dalam melakukan kegiatan transaksi mulai dari proses order, menyimpan data produk, mengubah data produk serta menghapus data produk sehingga menghasilkan informasi yang cepat, tepat, akurat dan menarik bagi pelanggan. Laman dinamis yang dibuat dengan rancangan yang terencana dengan baik akan menghasilkan laman yang memperjelas dan mempermudah dalam pengolahan data transaksi. Dengan pembuatan laman ini diharapkan dapat mengurangi bahkan mencegah terjadinya pencatatan kegiatan transaksi penjualan yang keliru, data penjualan yang hilang ataupun yang tidak sesuai dengan prosedur. Konsumen Akan mendapatkan Informasi yang Up to Date mengenai Sepatu yang baru pada laman website ini. Untuk pengembangan web kedepannya agar lebih baik dan menarik bagi pelanggan, peneliti juga memberikan saran yaitu agar laman ini dapat berjalan dengan baik, maka sebaiknya menggunakan perangkat keras yang memadai dan mendukung sarana yang ada, dibuat lebih mudah dalam penggunaannya dan mengurangi kesalahan yang mungkin terjadi. Perlu adanya back up data untuk antisipasi jika ada gangguan yang tidak terduga, sehingga data tetap dapat terkontrol dengan baik. Harus diberikan perawatan berkala, sehingga laman dapat berjalan dengan baik tanpa ada gangguan. Agar laman ini semakin cepat dikenal oleh masyarakat luas, maka dapat dimasukkan ke iklan media massa.

\section{Referensi}

Baliwati YF, Retnaningsih. 2004. Pengantar Pangan dan Gizi. Jakarta: Penebar Swadaya. Febrian

Hakim, Lukmanul. 2009. Trik Rahasia Master PHP Terbongkar Lagi. Yogyakarta : Lokomedia.

Jack. 2008. Kamus Komputer dan Teknologi Informasi. Penerbit Informatika.Bandung.

Kadir, Abdul. 2008. Dasar Pemograman Web Dinamis Menggunakan PHP. Yogyakarta: Andi Offset.

Kun, Toni. 2010. Membuat Website Canggih dengan jQuery untuk Pemula. Surabaya: MediaKita. 
MADCOMS. 2004. Aplikasi Program PHP dan MySQL Untuk Membuat Website Interaktif.Madiun: Penerbit Andi.

MADCOMS. 2008. Teknik Mudah Membangun Website dengan HTML, PHP, MySQL.Yogyakarta: Penerbit Andi.

Oetomo, Budi Sutedjo Dharma. 2007. Pengantar Teknologi Informasi Internet Konsep dan Aplikasi. Yogyakarta: ANDI.

Prihatna, Henky. 2005. Kiat Praktis Menjadi Webmaster Profesional. Jakarta: Elex Media Komputindo.

Salahhudin, M dan A.S, Rossa. 2008. Java di Web.Bandung CV.Informatika.

Simarmata, Janner. 2010. Rekayasa Web. Yogyakarta: Penerbit Andi Offset.

Martin. 2005. Pemrograman Database dengan Menggunakan Microsoft Visual Foxpro 9.0. Jakarta : PT. Elex Media Komputindo 